\title{
The role of sampling strategy on apparent temporal stability of soil moisture under subtropical hydroclimatic conditions
}

\author{
Lei Gao ${ }^{1,2}$, Yaji Wang ${ }^{1,3}$, Josie Geris ${ }^{2}$, Paul D. Hallett ${ }^{4}$, Xinhua Peng ${ }^{1 *}$ \\ ${ }^{1}$ State Key Laboratory of Soil and Sustainable Agriculture, Institute of Soil Science, Chinese Academy of Sciences, Nanjing 210008, \\ PR China. E-mail: lgao@issas.ac.cn \\ ${ }^{2}$ School of Geosciences, University of Aberdeen, Aberdeen, UK. E-mail: j.geris@abdn.ac.uk \\ ${ }^{3}$ University of Chinese Academy of Sciences, Beijing, 10049, China. E-mail: wangyaji@issas.ac.cn \\ ${ }^{4}$ School of Biological Sciences, University of Aberdeen, Aberdeen, UK. E-mail: paul.hallett@abdn.ac.uk \\ * Corresponding author. Tel.: +86 25 86881198. Fax: +86 25 86881000. E-mail: xhpeng@issas.ac.cn
}

\begin{abstract}
Subtropical regions have clay-rich, weathered soils, and long dry periods followed by intense rainfall that produces large fluctuations in soil water content (SWC) and hydrological behavior. This complicates predictions of spatiotemporal dynamics, as datasets are typically collected at too coarse resolution and observations often represent a duration that is too short to capture temporal stability. The aim of the present study was to gain further insights into the role of temporal sampling scale on the observed temporal stability features of SWC order to aid the design of optimal SWC sampling strategies. This focused on both sampling frequency and total monitoring duration, as previous analyses have not considered both of these sampling aspects simultaneously. We collected relatively high resolution data of SWC (fortnightly over 3.5 years) for various soil depths and under contrasting crops (peanuts and citrus) at the red soil region of southeast China. The dataset was split into a three-year training period and a six-month evaluation period. Altogether 13 sampling frequencies (intervals ranging from 15 to 240 days) and eight monitoring duration periods (between three and 36 months) were derived from the training period to identify temporal stability features and the most time stable location (MTSL). The prediction accuracies of these MTSLs were tested using the independent evaluation data. Results showed that vegetation type did affect the spatio-temporal patterns of SWC, whereby the citrus site exhibited a stronger temporal variation and weaker temporal stability than the peanut site. However, the effects of both sampling frequency and observation duration were more pronounced, irrespective of the role of vegetation type or soil depth. With increasing sampling interval or decreasing monitoring duration, temporal stability of SWC was generally overestimated; by less than $10 \%$ when sampling interval increased from every 15 to 240 days and by up to $40 \%$ with duration decreasing from 36 to 3 months. Our results suggest that sampling strategies and trade-offs between sampling interval and duration should focus on capturing the main variability in hydro-climatological conditions. For subtropical conditions, we found that sampling once every 45 days over 24 months to be the minimum sampling strategy to ensure errors in SWC temporal stability of less than $10 \%$.
\end{abstract}

Keywords: Sampling strategy; Subtropical climate; Temporal stability; Vegetation type; Soil moisture prediction.

Abbreviations: ARE: Absolute value of relative error; $\mathrm{CV}_{\mathrm{T}}$ : Coefficient of variation over time; MRD: Mean relative difference; MTSL: Most time stable location; RD: Relative difference; RE: Relative error; SDRD: Standard deviation of relative difference; SWC: Soil water content.

\section{INTRODUCTION}

Soil water content (SWC) exerts important controls on evapotranspiration and runoff generation processes (e.g. Boulet et al., 2015). It is a key state variable to many eco-hydrological models (Brandyk et al., 2016). In turn, SWC is a function of many factors, including soil texture, land use (including vegetation), soil depth, topography and climate (Canton et al., 2016), which leads to strong and nonlinear spatio-temporal variations in SWC dynamics (Buttafuoco et al., 2005).

Capturing such SWC patterns is therefore complex and challenging (Gao et al., 2016a), hence many studies seek to replace extensive SWC measurements with less labor-intensive approaches (e.g. Burns et al., 2016; Korres et al., 2015; Martini et al., 2015; Stockinger et al., 2014). Some efforts involve exploring novel sensing methodologies (e.g. via remote sensing or cosmic ray sensors (e.g. Zreda et al., 2012)) which integrate small scale heterogeneity and offer new insights into larger scale moisture dynamics. On the other hand, there is a need to increase efficiency of traditional point scale measurements, which still provide more accurate measurements locally than novel sensing methodologies. One common methodology to reduce those monitoring efforts is referred to as temporal stability, first put forward by Vachaud et al. (1985). It reflects the persistence of a spatial pattern of soil moisture in an area over time, which has been applied in many environments, ranging from humid (Gao et al., 2015b) to arid areas (Shen et al., 2016), and from forest (Korres et al., 2015) to agriculture ecosystems (Rivera et al., 2014).

The concept of temporal stability of SWC is widely used for various research and application purposes, for example to validate remotely sensed data (Cosh et al., 2006), optimize monitoring schemes (Brocca et al., 2010), fill in missing values (Dumedah and Coulibaly, 2011), assimilate data (Pan et al., 2012), estimate spatial mean SWCs (Biswas, 2014), predict spatial distribution ( $\mathrm{Hu}$ and $\mathrm{Si}, 2016)$, upscale from surface to profile scale (Gao et al., 2016b), downscale from field to plot scale (Nasta et al., 2018), and improve the space-time resolution of data (Zhu et al., 2017). The performance of these applications typically depends on the strength of temporal stability. It has been recognized that the sampling frequency (or interval) and the duration of the monitoring period are important compo- 
nents that affect the "apparent" features of temporal stability (Martínez et al., 2014; Vanderlinden et al., 2012).

Owing to variations in study aims and objectives, studies on temporal stability of SWC have used data which were collected at different sampling intervals, e.g. ranging from every $10 \mathrm{~min}$ (Guber et al., 2008), to daily (Heathman et al., 2009) to more than monthly (Wang et al., 2015b) and over different length of monitoring periods, e.g. ranging from approximately one month (Cosh et al., 2004) to one year (Li et al., 2016) to 10 years (Liu and Shao, 2014). This is a limiting factor to the generalization of the temporal stability application (Wang et al., 2015a), e.g. as it inhibits wider interpretations from individual studies. So far, those studies that considered the impact of sampling frequency did not find significant differences in temporal stability characteristics derived from data with sampling interval differences in the order of a few hours (Cosh et al., 2006), a few days (Guber et al., 2008) or one month (Martínez et al., 2014). However, the temporal stability index of each investigated frequency used in these studies was generally presented as the mean of all sub-datasets (e.g. Rivera et al., 2014), which mainly reflects the errors related to scale effects and ignores the uncertainties from a single sampling. Though the study of Cosh et al. (2006) compared the differences of temporal stability characteristics of different sampling intervals using single sampling strategy, the ranges of frequencies invested were limited, i.e. within 24 hours. In practice, however, single sampling at a specific interval, monthly or longer, is typically applied as a most costeffective strategy, and these results may be more affected by temporal sampling frequency than considering the mean of all sub-datasets (Hu et al., 2012).

Although the spatial pattern of SWC is generally time-stable, the "apparent" temporal stability strength could be affected by the span of the sampling period, as suggested by Vanderlinden et al. (2012). A few studies explored this issue but found inconsistent or even contradictory results. For example, Cosh et al. (2006) reported that the temporal stability of SWC was similar among four seasons and a whole year in the Washita watershed, southwestern Oklahoma. However, for an area in central Saskatchewan, Canada, Biswas and Si (2011) found that temporal stability with the same season was much stronger than between different seasons. Furthermore, for a site on the Loess Plateau, China, Liu and Shao (2014) found that the relationships between temporal stability and the duration of sampling period depended on the type of the vegetation based on a 10-year study period. These inconsistent results could be associated with different strengths of seasonal hydro-climatological variability mainly caused by the differences in climate, soil properties as well as vegetation type, as suggested by Martínez et al. (2014) and Wang et al. (2015a). It appears that such differences would be particularly evident in hydroclimatic regions where seasonal variability is extreme, such as tropical climates where long dry periods are followed by intense periods of rainfall.

Vegetation type and soil depth have been proven to be important factors that influence the temporal stability of SWC. Generally, vegetation activity appears to weaken the temporal stability of SWC (e.g. Cassel et al., 2000; Wang et al., 2015a), while the temporal stability typically increases with soil depth (e.g. Choi and Jacobs, 2007). Nevertheless, whether the influences of sampling strategy on temporal stability of SWC vary with vegetation types and soil depth in such areas with strong seasonal hydro-climatological variability is still unclear.

This study aims to gain further insights into the role of temporal sampling scales on the observed temporal stability of soil moisture. More specifically, the temporal sampling scales refers to the balance of how often in time and for how long a monitor- ing period in total. To explore these impacts under relatively extreme hydroclimatic conditions of the tropics, we investigate these at agricultural sites of the Chinese red soil region where strong climatic variability drives a highly dynamic soil moisture regime. Red soil is also an important resource of China and covers an area of 2.18 million $\mathrm{km}^{2}$. Seasonal drought from July to September is a big challenge faced in this region with regard to the productivity of crops (Zhao et al., 2012). In addition, the temporal stability concept has been proven to be an effective tool to improve agricultural water management in this region by providing precise SWC information (Gao et al., 2015b and 2016a). Optimizing sampling strategies is important so that temporal stability can be effectively characterized in this region.

The specific objectives were to 1) identify spatio-temporal patterns of SWC for two contrasting cropping practices at four soil layers in an agricultural landscape of the Chinese Red soil region; 2) for these different sites, evaluate the role of sampling frequency (i.e. the interval between sampling occasions) and the duration of the monitoring period on temporal stability features and mean SWC prediction and 3) based on the outcomes of (1) and (2), explore potential applications to inform temporal sampling strategies for similar temporal stability studies.

\section{MATERIALS AND METHODS} Study area

SWC data were collected in the Sunjia agricultural catchment $\left(116^{\circ} 53^{\prime} 58^{\prime \prime}-116^{\circ} 54^{\prime} 28^{\prime \prime} \mathrm{E}, 28^{\circ} 13^{\prime} 45^{\prime \prime}-28^{\circ} 14^{\prime} 12^{\prime \prime} \mathrm{N}\right)$, a recognized Critical Zone Observatory located in Yingtan, Jiangxi province, China (Fig. 1). The area has a typically warm and humid subtropical monsoon climate. Mean annual precipitation is $\sim 1800 \mathrm{~mm}$ and annual potential evapotranspiration is $\sim 1200 \mathrm{~mm}$. There is a strong climatic seasonality with a distinct dry (July to September) and wet (April to June) season. The dry season receives less than $20 \%$ of annual rainfall, while potential evapotranspiration rates amount to more than $45 \%$ of the annual total. In contrast, more than $50 \%$ of the annual precipitation occurs during the wet season (Zhao et al., 2012).

The dominant crop types for upland at Sunjia are peanut (Arachis hypogaea) and citrus (Citrus reticulata), which have distinctly different patterns in root water absorption (Tahir et al., 2016). Cultivation histories of the two vegetation types are approximately 25 years, both of which replaced tea plantations (Camellia sinensis) in the early 1990s. The growing seasons for peanut is from April to August and for citrus from April to October. Unlike rice fields in the region, both peanut and citrus do not receive any irrigation water.

Soils at the study site were derived from Quaternary red clays and are classified as Ultisols based on the USDA Soil Taxonomy classification system (Soil Survey Staff, 2010). Although the overall soil classification is similar, there are differences in the soil physical properties associated with the two vegetation types. Key differences include a higher clay content and soil organic carbon content for soils at the citrus site than those at the peanut site (Table 1). In addition, the saturated hydraulic conductivity of soils under peanut is up to an order of magnitude higher than under citrus at surface $20 \mathrm{~cm}$ soil layer (Table 1). This can be associated with the different soil management practices (i.e. tillage) for peanut and citrus.

\section{Data collection}

Nine monitoring locations with an approximate spacing of $15 \mathrm{~m}$ in a transect along the slope were chosen for each vegeta- 
Table 1. Soil properties of different soil layers within $0-100 \mathrm{~cm}$ for peanut and citrus sites.

\begin{tabular}{|c|c|c|c|c|c|c|c|}
\hline $\begin{array}{l}\text { Vegetation } \\
\text { type }\end{array}$ & $\begin{array}{c}\text { depth } \\
\mathrm{cm}\end{array}$ & $\begin{array}{c}\text { Sand } \\
\%\end{array}$ & $\begin{array}{c}\text { Silt } \\
\%\end{array}$ & $\begin{array}{c}\text { Clay } \\
\%\end{array}$ & $\begin{array}{l}\mathrm{BD}^{*} \\
\mathrm{~g} / \mathrm{cm}^{3}\end{array}$ & $\begin{array}{c}\mathrm{SOC}^{*} \\
\mathrm{~g} / \mathrm{kg}\end{array}$ & $\begin{array}{c}K_{S}^{*} \\
\mathrm{~cm} / \text { day }\end{array}$ \\
\hline \multirow{5}{*}{ Peanut } & $0-20$ & $38.4 \pm 9.3$ & $27.5 \pm 4.3$ & $34.1 \pm 5.4$ & $1.34 \pm 0.12$ & $10.7 \pm 3.0$ & $162.7 \pm 104.1$ \\
\hline & $20-40$ & $35.1 \pm 10.0$ & $28.6 \pm 4.1$ & $36.3 \pm 7.4$ & $1.41 \pm 0.09$ & $5.3 \pm 1.4$ & $16.2 \pm 27.6$ \\
\hline & $40-60$ & $36.3 \pm 7.8$ & $27.1 \pm 3.2$ & $36.7 \pm 5.9$ & $1.40 \pm 0.11$ & $4.0 \pm 0.7$ & $16.4 \pm 15.6$ \\
\hline & $60-80$ & $34.7 \pm 7.8$ & $27.3 \pm 3.1$ & $38.0 \pm 6.2$ & $1.38 \pm 0.12$ & $3.7 \pm 0.9$ & $13.8 \pm 18.1$ \\
\hline & $80-100$ & $33.6 \pm 7.0$ & $27.2 \pm 3.6$ & $39.2 \pm 5.5$ & $1.42 \pm 0.09$ & $3.2 \pm 0.7$ & $9.6 \pm 9.1$ \\
\hline \multirow{4}{*}{ Citrus } & $0-20$ & $41.3 \pm 4.3$ & $24.9 \pm 2.1$ & $33.8 \pm 3.1$ & $1.38 \pm 0.08$ & $13.6 \pm 2.6$ & $18.8 \pm 12.5$ \\
\hline & $40-60$ & $33.5 \pm 2.9$ & $24.4 \pm 1.6$ & $42.1 \pm 4.0$ & $1.45 \pm 0.11$ & $3.6 \pm 0.5$ & $5.7 \pm 8.0$ \\
\hline & $60-80$ & $33.8 \pm 5.0$ & $26.0 \pm 4.8$ & $40.2 \pm 5.7$ & $1.41 \pm 0.06$ & $3.2 \pm 0.6$ & $8.8 \pm 7.2$ \\
\hline & $80-100$ & $34.7 \pm 4.1$ & $24.5 \pm 5.5$ & $40.8 \pm 8.2$ & $1.45 \pm 0.08$ & $2.7 \pm 0.4$ & $10.4 \pm 12.8$ \\
\hline
\end{tabular}

$* \mathrm{BD}=$ bulk density; $\mathrm{SOC}=$ soil organic carbon; $K_{S}=$ soil saturated hydraulic conductivity. All the values were the mean values of nine locations by arithmetic method.

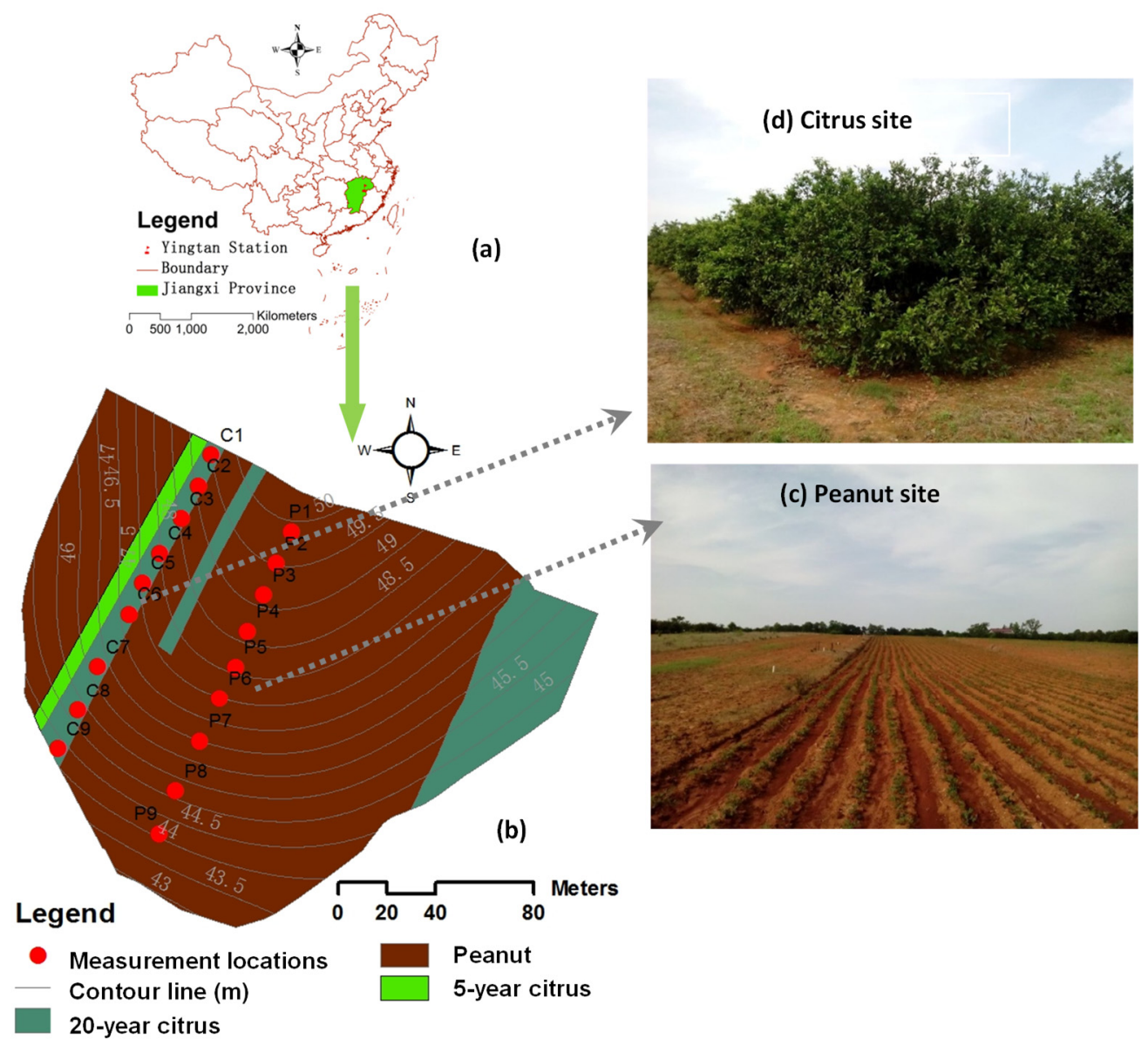

Fig. 1. Location of the studied slope (a) and spatial distribution of monitoring locations across the slope (b) for peanut (c) and citrus (d) sites.

tion type to measure SWC (see Fig. 1). To eliminate possible influences from topography and climate, the two transects were nearly parallel along the same slope with peanut and citrus, respectively. The topography of the two transects was similar, with a slope length of approximately $150 \mathrm{~m}$ and the elevation ranging from 44 to $50 \mathrm{~m}$ (Fig. 1). Soil layer thickness for both transects varied between approximately $5.0 \mathrm{~m}$ and $6.5 \mathrm{~m}$ depending on slope position. A 2-m polyvinyl chloride access tube with a diameter of $5 \mathrm{~cm}$ was installed at each location in early 2013. Each tube was capped at the bottom with a watertight seal, and a removable cap was placed on top to prevent water entering the tube.

The volumetric SWC was measured using a size-matched portable TDR TRIME-PICO-IPH probe, with the length of 18 $\mathrm{cm}$, measuring accuracy of $2 \%$ and repeat accuracy $0.3 \%$
(IMKO, Ettlingen, Germany). Since properties of the studied soil were within those ranges tested and calibrated by the manufacturer, we initially used the factory-set calibration curve to translate the dielectric constant of the soil into SWC. In addition, to avoid drifts in the data of this portable probe, its consistency was checked via a calibration in dry and watercovered glass beads (the depth of water film lower than $2 \mathrm{~mm}$ ) every two months (see also Zhu et al., 2017). This involved the standard procedure recommended in the user manual. From July 2013 to December 2016, with an approximate time interval of 15 days, SWC was collected at $20 \mathrm{~cm}$ intervals to a depth of $160 \mathrm{~cm}$ on 79 occasions. For the purpose of this study, at each sampling date, the collected SWCs were transferred to mean values for layers of $0-40,40-80,80-120$, and $120-160 \mathrm{~cm}$ soil depth. 


\section{Data analysis}

First, the 3.5-year dataset was used to identify general temporal variations and temporal stability of SWC in the study area. Next, to test the impacts of the sampling strategy on the behavior of temporal stability, the full dataset was split into a training period (from July, 2013 to June, 2016) and evaluation period (from July to December, 2016). A range of sampling frequencies (varying intervals between sampling occasions) and periods (varying total duration of the monitoring period) were obtained from the training period by re-sampling analysis. For each sampling strategy, temporal stability analysis was performed to obtain the temporal stability index and identify the MTSL. The evaluation period was used to evaluate the prediction accuracy based on the identified MTSLs.

\section{Re-sampling analysis}

The dataset of the 36 months training period was re-sampled for 13 sampling intervals (once every 15, 30, 45, 60, 75, 90, $105,120,135,150,180,210$ and 240 days) and eight sampling duration periods $(36,30,24,18,12,9,6$, and 3 months). All of the possible sub-datasets for each sampling strategy were obtained to cover the whole training period. The aim of getting all the possible sub-datasets was to separate the changes of temporal stability caused by the temporal uncertainty of SWC and by temporal sampling scale itself.

The number of sub-datasets for each sampling interval was determined by its value divided by the shortest sampling interval (i.e. 15 days). For example, for the sampling strategy with 120-day sampling interval, the number of the sub-dataset was eight (i.e. 120 by 15). The approach to obtain the eight subdatasets is that beginning from eight different dates (from the first, second and until the eighth date) with the same sampling interval of 120 days (see Fig. 2a).

Similarly, the number of the sub-datasets for each sampling period duration was calculated based on the longest period (i.e. 36 months) and the period of the sub-dataset. For example, the number of the sub-datasets for a 6-month sampling period is calculated from 36 months by six months. The six sub-datasets were obtained beginning from the first, seventh, $13^{\text {th }}$ until $31^{\text {st }}$ month with 6-month duration (see Fig. 2b).

\section{Temporal stability analysis}

Relative difference analysis was used to evaluate the temporal stability of SWC with the mean relative difference
(MRD) and standard deviation of relative difference (SDRD) indices. Relative difference (RD) is the difference between an individual measurement of SWC at location $i$ time $j$, $S W C_{j}(i)$, and the mean $S W C, \overline{S W C_{j}}$ of the same time. It provides an estimation of the unbiased difference between them:

$$
R D_{j}(i)=\frac{S W C_{j}(i)-\overline{S W C_{j}}}{\overline{S W C_{j}}}
$$

where

$$
\overline{S W C_{j}}=\frac{1}{N} \sum_{i=1}^{N} S W C_{j}(i)
$$

$N$ is the number of measurement locations ( $N=9$ in the present study).

Temporal mean $R D$ and its standard deviation at location $i$, $M R D(i)$ and $S D R D(i)$ are defined as:

$$
\operatorname{MRD}(i)=\frac{1}{m} \sum_{j=1}^{m} R D_{j}(i)
$$

and

$$
S D R D(i)=\sqrt{\frac{1}{m-1} \sum_{j=1}^{m}\left(R D_{j}(i)-M R D(i)\right)^{2}}
$$

for which $m$ is the number of measurement occasions, totaling 67 for the training period and 79 for the whole study period. The MRD and SDRD represent the bias and the precision of the location when used for predicting the mean SWC, respectively. In this study, the location with the lowest SDRD values was chosen as the MTSL, which can be used to predict the mean SWC with an offset by the corresponding MRD value (Starks et al., 2006):

$$
\overline{S W C_{j}}=\frac{S W C_{j}(i)}{1+M R D(i)}
$$

Here, we could not obtain the true value of the temporal stability index from the field data. One alternative to overcome this is to employ the dataset with the longest sampling period and the shortest sampling interval for temporal stability analysis. As such, the temporal stability index (i.e. SDRD) of the full dataset (i.e. 15-day sampling interval over 36 months) was here considered as the "true value", while the SDRD of any of the
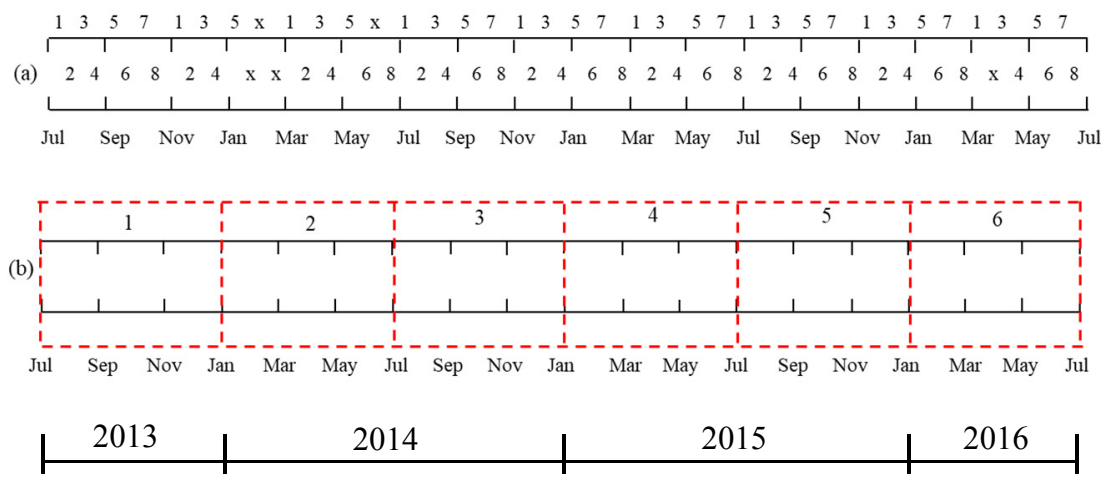

Fig. 2 Example diagrams of sampling strategies explored in the present study, showing the structure of 120 days as an example for sampling intervals (a) and 6 months for sampling periods (b). For (a): the sampling occasions with the same number belong to the same subdataset; numbers 1-8 represent the eight sub-datasets and $x$ are occasions for which no data were available. For (b): numbers 1-6 represent the six sub-datasets with the same sampling interval of 15 days (not shown in the schematic). 
sub-sets was the "apparent" value (cf., Rivera et al., 2014; Western and Blöschl, 1999). The scale effect on temporal stability was reflected by the deviation of mean SDRD values of all sub-datasets to the "true value" for each sampling strategy.

The error introduced by a single sampling related to neglecting of inner variations, considered as the "uncertainty" here, was reflected by the maximum deviation in all the sub-datasets. Using the dataset of the evaluation period, the prediction accuracy was assessed by the deviation between the observed and predicted mean SWCs. The deviations between "apparent" SDRD and its "true value" and between the predicted mean SWC and observed SWC were expressed by the index of relative error (RE) and the related maximum RE (Max-RE), absolute value of relative error (ARE) and its mean and maximum, Mean-ARE and Max-ARE.

\section{RESULTS}

\section{Spatio-temporal patterns in soil water content (SWC)}

Dynamics of spatial mean SWC (nine locations along the slope for each vegetation type) during the full study period (from July 2013 to December 2016) suggested that both vegetation type and soil depth affected the temporal variation of SWC (Fig. 3). Overall, temporal variations of SWC for citrus were stronger than for peanut. This is evident across the full depth range, where the coefficients of variation over time $\left(\mathrm{CV}_{\mathrm{T}}\right)$ were consistently higher for citrus than for peanut (Table 2). It was also found that the differences of the variation between the two vegetation types were larger for deeper soil depths than shallow ones (Table 2).

The temporal stability of SWC, denoted by SDRD, was stronger for peanut than citrus at all four soil layers (Table 2). The location of the MTSLs, identified by the lowest SDRD values, varied with depth for both peanut and citrus. For example, the MTSLs for peanut were at P6 for the $0-40 \mathrm{~cm}$ depth, while at $\mathrm{P} 3$ for the other three depth ranges. For citrus, these locations were P7 and P1, respectively (Table 2).

\section{Influences of temporal sampling strategies on temporal stability of SWC}

In general, sampling frequency affected the averaged SDRD values only slightly (Fig. 4). Compared to the "true value", the relative errors (REs) of 91 out of 104 cases (13 sampling intervals at four soil layers for two vegetation types in total) were lower than 5\% (RE values not shown in Figure 4). This was the case for all sampling interval increases from every 15 days up to 150 days. However, when the sampling interval was longer than once every 150 days, the SDRD was increasingly underestimated. Accordingly, the largest ARE (12.7\%) was derived for the longest sampling interval (i.e. 240-days).

The maximum REs (Max-REs) of sampling strategies increased largely with longer sampling intervals. This was inde-
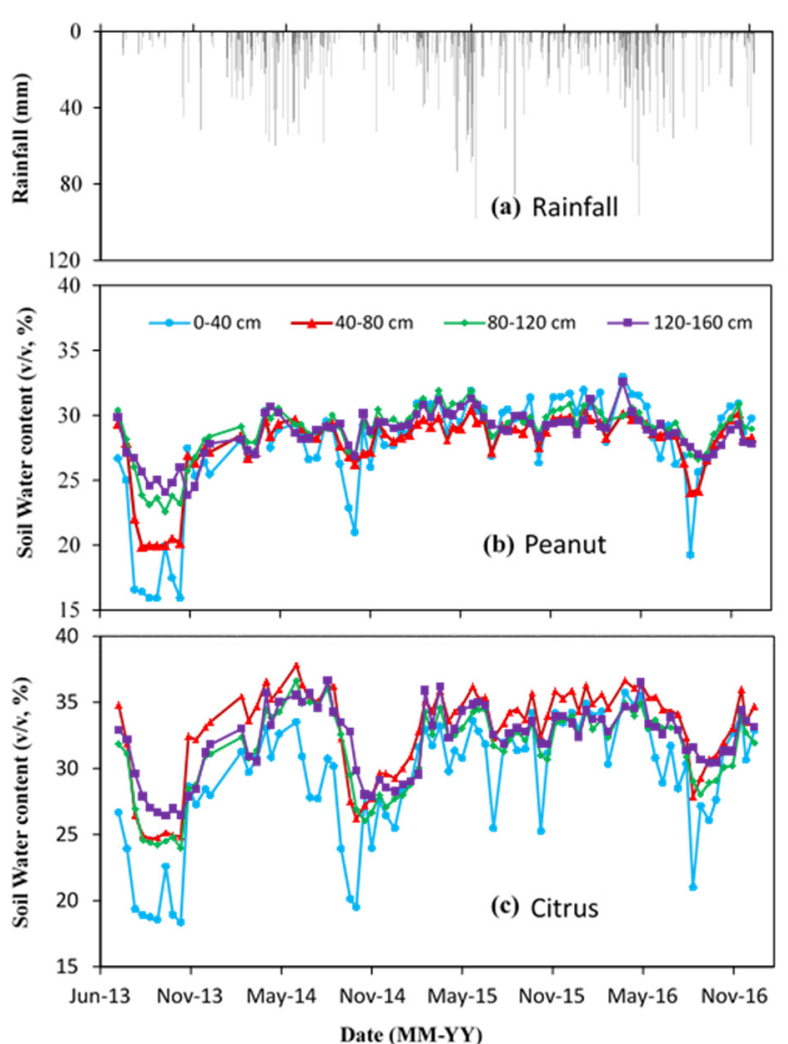

Fig. 3. Temporal dynamics of rainfall (a) and spatial mean soil water content (SWC) from July, 2013 to December, 2016 for peanut (b) and citrus sites (c) at 0-40, 40-80, 80-120, and 120-160 $\mathrm{cm}$ soil layers.

pendent of depth where all the errors over $50 \%$ occurred for the longest sampling interval (i.e. once every 240 days) for all the four soil depth ranges (Fig. 4). When the sampling interval was shorter than 60 days (i.e. every 15, 30, and 45 days), corresponding Max-REs were less than $10 \%$ (Fig. 4). However, for some cases, such as $40-80$ and $80-120 \mathrm{~cm}$ for the peanut site, the Max-REs were even less than $10 \%$ when sampling intervals were 90 days or less (Fig. 4). Significant differences were found for the peanut site among four soil depths except for the 40-80 vs. $80-120 \mathrm{~cm}$ soil layer $(\mathrm{p}<0.05$, t-test). For the citrus site, however, only the error of the $0-40 \mathrm{~cm}$ soil layer was significantly less than those of the 80-120 and 120-160 cm soil layers.

Changes of averaged SDRD values with the sampling period increasing from 3 months to 36 months could be divided into two stages: slight fluctuations for a sampling duration $>12$ month, but a fast increase when duration changed from 3 to 12 months. For durations $>12$ months, the AREs for SDRD were generally less than $10 \%$ for both peanut and citrus (Fig. 5). However, AREs rose sharply to more than $30 \%$ for sampling durations $<12$ months (Fig. 5). The generally negative errors

Table 2. Statistics of soil water content (SWC) from July, 2013 to December, 2016 of temporal mean values, temporal coefficient of variation $\left(\mathrm{CV}_{\mathrm{T}}\right)$, mean standard deviation of relative difference (SDRD), most temporal stability location (MTSL) based on the method with the lowest SDRD values at $0-40,40-80,80-120$, and $120-160 \mathrm{~cm}$ soil layers for peanut and citrus sites.

\begin{tabular}{|c|c|c|c|c|c|c|c|c|}
\hline \multirow{2}{*}{ Soil depth (cm) } & \multicolumn{4}{|c|}{ Peanut } & \multicolumn{4}{|c|}{ Citrus } \\
\hline & $0-40$ & $40-80$ & $80-120$ & $120-160$ & $0-40$ & $40-80$ & $80-120$ & $120-160$ \\
\hline Mean SWC & $27.6 a$ & $27.8 \mathrm{a}$ & $28.9 \mathrm{a}$ & $28.6 \mathrm{a}$ & $29.2 \mathrm{a}$ & $32.9 \mathrm{~b}$ & $31.3 \mathrm{a}$ & $32.1 \mathrm{~b}$ \\
\hline $\mathrm{CV}_{\mathrm{T}}$ & 15.0 & 9.5 & 7.1 & 6.1 & 15.9 & 10.6 & 10.3 & 8.2 \\
\hline MTSL & P6 & $\mathrm{P} 1$ & $\mathrm{P} 1$ & $\mathrm{P} 1$ & P7 & P3 & P3 & P3 \\
\hline SDRD of MTSL & 2.6 & 1.6 & 2.6 & 4.0 & 3.0 & 3.3 & 3.2 & 3.4 \\
\hline
\end{tabular}

Mean SWCs flowed by different letters indicating significantly different between peanut and citrus sites ( $\mathrm{p}<0.05$, paired samples t-test). 


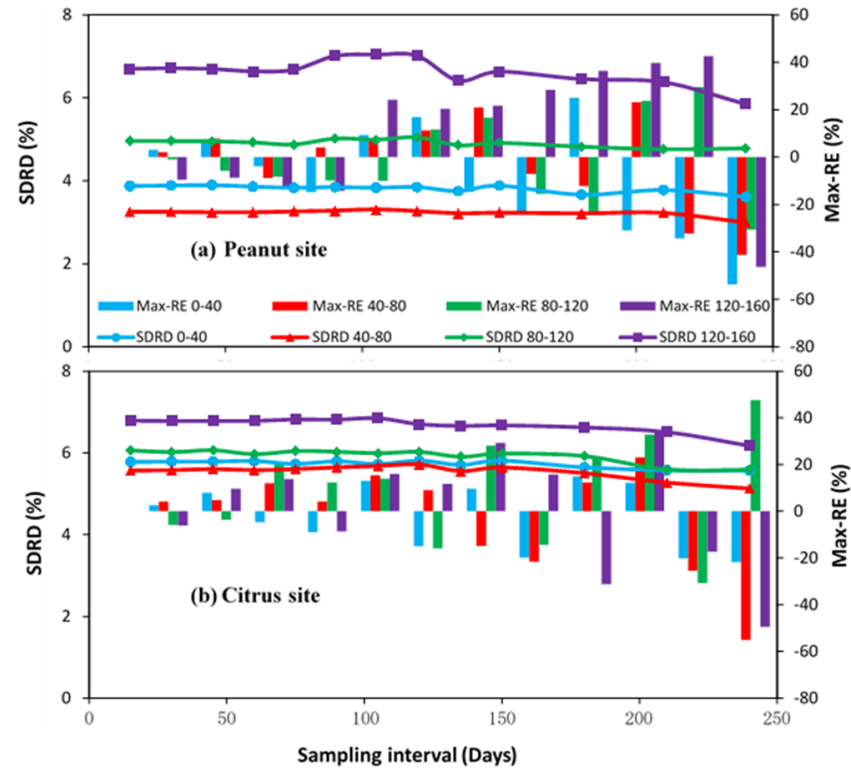

Fig. 4. Changes of temporal stability of soil water content (SWC) with 13 sampling intervals for peanut (a) and citrus (b) sites at $0-40,40-80,80-120$, and 120-160 cm soil layers during the training period (from July, 2013 to June, 2016), represented by the standard deviation of relative difference (SDRD) and its maximum relative error (Max-RE) of sub-datasets.

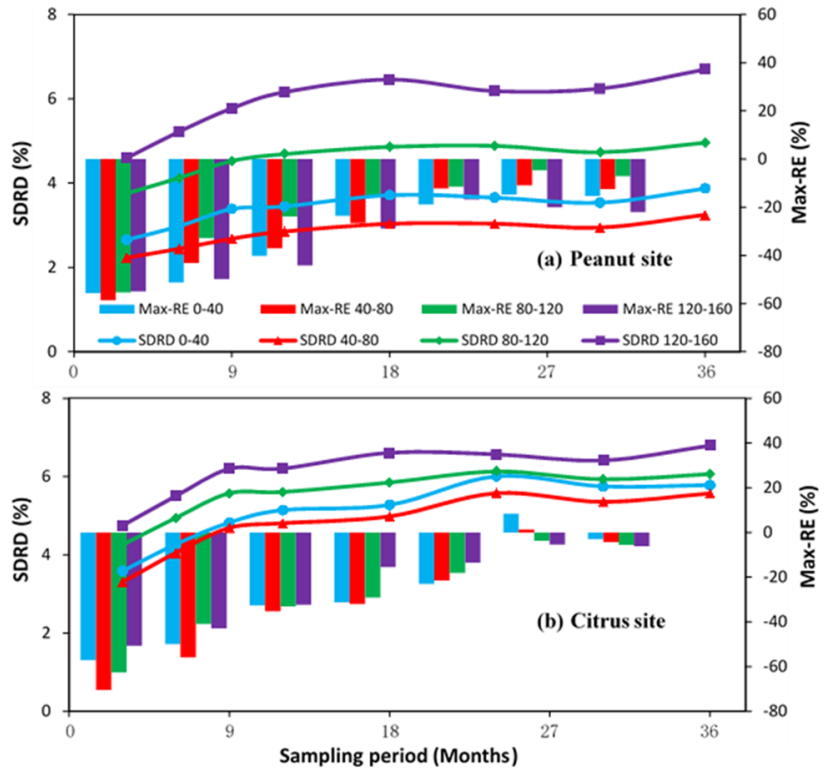

Fig. 5. Changes of temporal stability of soil water content (SWC) with eight sampling periods for peanut (a) and citrus (b) sites at $0-40,40-80,80-120$, and $120-160 \mathrm{~cm}$ soil layers during the training period (from July, 2013 to June, 2016), represented by the standard deviation of relative difference (SDRD) and its maximum relative error (Max-RE) of sub-datasets.

Table 3. Criterion of sampling interval and period to meet standard deviation of relative difference (SDRD) and soil water content (SWC) prediction with mean absolute value of relative error (Mean-ARE) over all sub-datasets lower than $10 \%$ for peanut and citrus sites at $0-40$, $40-80,80-120$, and $120-160 \mathrm{~cm}$ soil layers.

\begin{tabular}{|c|c|c|c|c|c|}
\hline \multirow{2}{*}{ Vegetation type } & \multirow{2}{*}{$\begin{array}{c}\text { Soil depth } \\
\mathrm{cm}\end{array}$} & \multicolumn{2}{|c|}{ Sampling interval } & \multicolumn{2}{|c|}{ Sampling period } \\
\hline & & SDRD & Mean SWC & SDRD & Mean SWC \\
\hline \multirow{4}{*}{ Peanut } & $0-40$ & $240(4)$ & $240(4)$ & $12(23)$ & $3(5)$ \\
\hline & $40-80$ & $240(4)$ & $240(4)$ & $18(34)$ & $3(5)$ \\
\hline & $80-120$ & $240(4)$ & $240(4)$ & $9(17)$ & $3(5)$ \\
\hline & $120-160$ & $210(5)$ & $240(4)$ & $12(23)$ & $3(5)$ \\
\hline \multirow{4}{*}{ Citrus } & $0-40$ & $240(4)$ & $240(4)$ & $12(23)$ & $3(5)$ \\
\hline & $40-80$ & $240(4)$ & $240(4)$ & $18(34)$ & $3(5)$ \\
\hline & $80-120$ & $240(4)$ & $240(4)$ & $9(17)$ & $3(5)$ \\
\hline & $120-160$ & $240(4)$ & $240(4)$ & $9(17)$ & $3(5)$ \\
\hline
\end{tabular}

Number in the brackets stands for the occasions of sampling required.

Table 4. Criterion of sampling interval and period to meet standard deviation of relative difference (SDRD) and soil water content (SWC) prediction with maximum absolute value of relative error (Max-ARE) over all sub-datasets lower than $10 \%$ for peanut and citrus sites at $0-40,40-80,80-120$, and $120-160 \mathrm{~cm}$ soil layers.

\begin{tabular}{|c|c|c|c|c|c|}
\hline \multirow[t]{2}{*}{ Vegetation type } & \multirow{2}{*}{$\begin{array}{l}\text { Soil depth } \\
\mathrm{cm}\end{array}$} & \multicolumn{2}{|c|}{ Sampling interval } & \multicolumn{2}{|c|}{ Sampling period } \\
\hline & & SDRD & Mean SWC & SDRD & Mean SWC \\
\hline \multirow{4}{*}{ Peanut } & $0-40$ & $60(17)$ & $45(22)$ & - & $24(46)$ \\
\hline & $40-80$ & $90(12)$ & $105(10)$ & - & $12(23)$ \\
\hline & $80-120$ & $90(12)$ & $180(6)$ & $24(46)$ & $6(11)$ \\
\hline & $120-160$ & $45(22)$ & $105(10)$ & - & $12(23)$ \\
\hline \multirow{4}{*}{ Citrus } & $0-40$ & $75(14)$ & $75(14)$ & $24(46)$ & $18(34)$ \\
\hline & $40-80$ & $45(22)$ & $60(17)$ & $24(46)$ & $24(46)$ \\
\hline & $80-120$ & $45(22)$ & $90(12)$ & $24(46)$ & $18(34)$ \\
\hline & $120-160$ & $45(22)$ & $90(12)$ & $24(46)$ & $9(17)$ \\
\hline
\end{tabular}

“_." means that no investigated sampling frequency or sampling period meeting the requirement.

suggest that the temporal stability of SWC was overestimated for short sampling periods. For the shortest sampling period duration (i.e. 3 months), the mean errors of sub-datasets were highest.
The differences in Max-AREs among soil layers for peanut site were significant except for $0-40$ vs. $40-80 \mathrm{~cm}$ and $0-40$ vs. $120-160 \mathrm{~cm}$ soil layers $(\mathrm{p}<0.05$, t-test) while no significant differences were observed among any of the soil layers for the 
citrus site. Significant differences between the two vegetation types were observed at deeper soil layers (i.e. 80-120 and 120$160 \mathrm{~cm}$ ). Nevertheless, changing sampling frequency and duration did not change the ranks of relative magnitude for mean SDRD for both peanut and citrus sites, which were identical to that under the full dataset.

The errors of temporal stability with changing sampling intervals from scale effects (Mean-RE) and from the uncertainties (Max-REs) varied greatly. Taking the longest sampling interval (i.e. every 240 days) for the 36 -month period as an example, the two sources of errors were $-6.7 \%$ vs. $-53.7 \%,-7.9 \%$ vs. $-41.3 \%,-3.5 \%$ vs. $-30.6 \%$, and $-12.7 \%$ vs. $-46.3 \%$ for peanut and $-3.7 \%$ vs. $-21.8 \%,-7.9 \%$ vs. $-55.1 \%,-7.8 \%$ vs. $-47.6 \%$, and $-9.1 \%$ vs. $-49.4 \%$ for the citrus site. The ratios between the scale effect and uncertainties from the temporal variation of inner scale ranged from 0.1 to 0.4 . However, the differences of the errors from the two sources become more comparable when the sampling period decreased from 36 months to 3 months, with the ratio changing from $0.8-1.5$.

Requirements for sampling intervals and period duration to meet the criterion of ARE less than $10 \%$ for the mean and maximum SDRD of all sub-datasets are shown in Tables 3 and 4 , respectively. Long sampling periods appeared to be required to meet the criterion. For example, around 5 sampling occasions were sufficient to ensure the AREs of mean SDRD were less than $10 \%$ for a total sampling duration of 36 months. However, corresponding sampling occasions need to be increased to 17-34 sampling occasions for shorter monitoring periods (Table 3 ). Both sampling interval and period duration required should improve largely to meet the maximum errors of all the subdatasets lower than $10 \%$ (Table 4). For example, the sampling interval should not be longer than 60 days for peanut at $0-40$ $\mathrm{cm}$ to obtain Max-ARE of all the sub-datasets around 10\% (Table 4). For some extreme cases, i.e. citrus site at $0-40$, 40-80, and 120-160 cm, Max-AREs were consistently higher than $10 \%$ for all the investigated sampling periods.

\section{Influences of temporal sampling strategy on mean SWC prediction}

Prediction accuracy was generally high for most sampling strategies. Figures 6 and 7 show that Mean-ARE is always less than $5 \%$ except for citrus with a short sampling period, e.g. 3 or 6 months (Fig. 7). These high prediction accuracies suggested that the temporal stability technique would generally be an appropriate tool for mean SWC prediction, even for a long sampling interval (e.g. once every 240 days) or for short sampling periods (e.g. 3 months).

Mean-AREs were more constant with changing sampling frequencies than sampling periods. Taking the citrus site as an example, when the sampling interval increased from 15 days (67 occasions) to 210 days (5 occasions), the Mean-AREs remained more or less the same for the four soil layers (Fig. 6), but with decreasing sampling period from 36 months (67 occasions) to 3 months ( 5 occasions), they increased consistently (Fig. 7). Max-AREs, however, increased much more with increasing sampling intervals and decreasing periods compared to mean errors. For example, the Max-AREs increased from $4.2 \%$ to $16.1 \%$ for peanut and from $5.7 \%$ to $21.7 \%$ for citrus at $0-40$ $\mathrm{cm}$ when sampling intervals increased from 15 days to 240 days (Fig. 6).

Generally, the prediction accuracy of mean SWC was better for the peanut than the citrus site. The Mean-AREs of the different sampling frequencies for peanut were lower than for citrus at all four soil layers $(\mathrm{p}<0.05$, $\mathrm{t}$-test $)$, with the mean values of $2.5 \%$ vs. $3.6 \%, 1.7 \%$ vs. $3.1 \%, 1.7 \%$ vs. $4.2 \%$ and $2.2 \%$ vs. $2.6 \%$, respectively (Fig. 6 ). Relative to the differences between the two vegetation types, the differences among soil layers were smaller. No significant differences were observed in the Mean-AREs between 0-40 and 120-160 cm and between $40-80$ and $80-120 \mathrm{~cm}$ soil layers $(\mathrm{p}>0.05$, t-test).

\section{DISCUSSION}

Influence of vegetation on spatio-temporal patterns in SWC

Soil water content of peanut and citrus sites exhibited different spatio-temporal patterns: stronger temporal variations, weaker temporal stability and lower mean SWC prediction accuracies were found under citrus than for peanut. Such differences may be related to (a combination of) the differences in soils and vegetation characteristics between them.

Firstly, soils at the citrus site have generally more clay compared to those at the peanut site (Table 1). These differences in clay can be mainly related to a different degree of soil erosion (Jarasiunas and Kinderiene, 2016) which is higher for peanut than for citrus. In general, agriculture has shown to exacerbate soil erosion in this region. Zhao et al. (2012) reported that soil loss under crop production was three times higher than under forest land use. By preferentially removing clay, soil erosion can increase sand and decrease clay contents for agricultural soils (Lai, 1998). Higher clay content is generally associated with relatively weaker temporal variation of SWC (Wang et al., 2017). This was inconsistent with observations in the present study, which showed that citrus had a larger clay content and stronger temporal variation in SWC.

In addition, relative differences in soil hydraulic properties between the two vegetation types do not directly support the stronger temporal variation of SWC for the citrus site. Due to the traditional tillage at the peanut site (generally in late March), the Ks of soils under this land use was 6-9 times higher than that at the citrus site at $0-20 \mathrm{~cm}$ soil at the time of sampling (early May, 2014). However, there is also a strong temporal variability in the soil hydraulic properties, which might not fully reflect the differences between sites as presented in Table 1. For example, for the same hillslope and based on tension infiltrometer data, Zhang et al. (2016) found that the temporal variation in soil effective porosity and site contribution to water flux for a tilled crop (watermelon) was much stronger than for citrus.

As such, the diverse temporal dynamics in soil moisture under citrus may be related to the characteristics of vegetation. In addition to the preferential flow in root channels, root water uptake could also explain the differences observed between the moisture dynamics. Citrus trees generally use more water with uptake from over a larger range of depth $(>100 \mathrm{~cm})$ than a peanut crop (within $20 \mathrm{~cm}$ ). Therefore, citrus trees could be associated with stronger temporal SWC dynamics by decreasing the SWC in the dry season and allowing for more water storage in soils during the rainy and winter seasons (Fader et al., 2015). This may be exemplified by the sharp drop in the SWC in September 2014, which was more pronounced for citrus than for the peanut site (Fig. 3).

\section{Responses of "apparent" temporal stability to temporal sampling strategies}

Results showed that the temporal stability of SWC has a tendency to be overestimated with increasing sampling intervals (only when $>150$ days) and decreasing the total duration of the sampling period. The extent of the overestimation was 
The role of sampling strategy on apparent temporal stability of soil moisture under subtropical hydroclimatic conditions

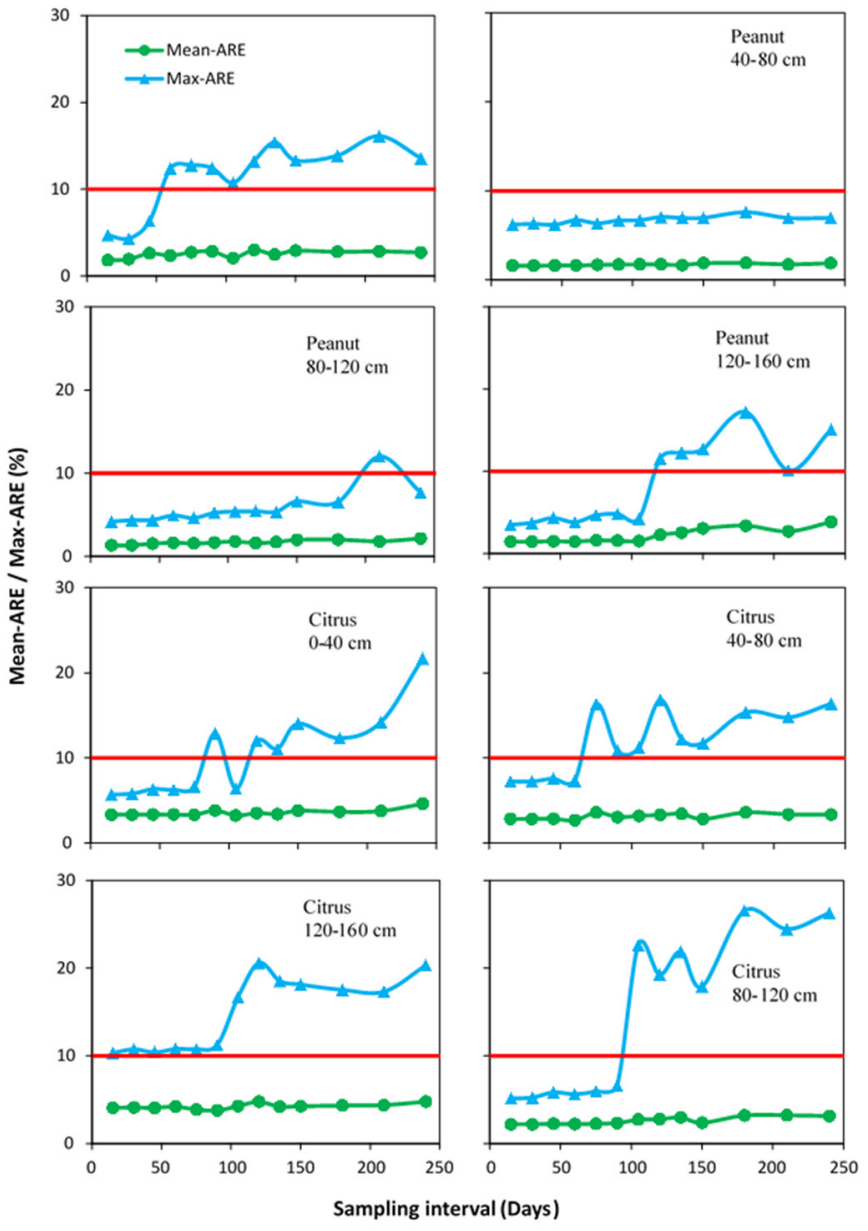

Fig. 6. Changes of prediction accuracy of soil water content (SWC) with 13 sampling intervals for peanut (a) and citrus (b) sites at $0-40,40-80,80-120$, and $120-160 \mathrm{~cm}$ soil layers during the validation period (from July, 2016 to December, 2016), represented by the mean value and maximum of absolute value of relative error, Mean-ARE and Max-ARE, respectively.

much lower with increasing sampling intervals than for decreasing the duration of the monitoring period.

In the present study area, seasonal dynamics of SWC were strong (see Fig. 3), which appears to affect the temporal stability of SWC due to the seasonal controlling factors such as meteorological effects (Cho et al., 2016) and vegetation characteristics (Wang et al., 2015a). The overestimation could be due to the neglect of the variation within or between seasons when sampling frequency is low (e.g. less than one season) or when the total sampling period is short (e.g. shorter than one whole season cycle). Such under-sampled variation would have a general tendency to lead to an overestimation of temporal stability, as suggested previously by Biswas (2014) and Gao et al. (2015a). In addition, large study extent generally leads to high similarity of the spatial patterns, which decreases the requirements of the temporal sampling strategy (Zhang et al., 2015). As such, the temporal sampling strategy may play a less important role in affecting the "apparent" temporal stability features in areas with weak seasonal patterns or at a relatively large spatial scale. SDRD values were much more constant with changing sampling intervals (Fig. 4) than sampling duration periods (Fig. 5). These diverse influences are probably related to the "aliasing" effect, which refers to the effect of spatial or temporal inner information partly "folded back" from low frequency to high frequency in sampling theory (Jenkins and
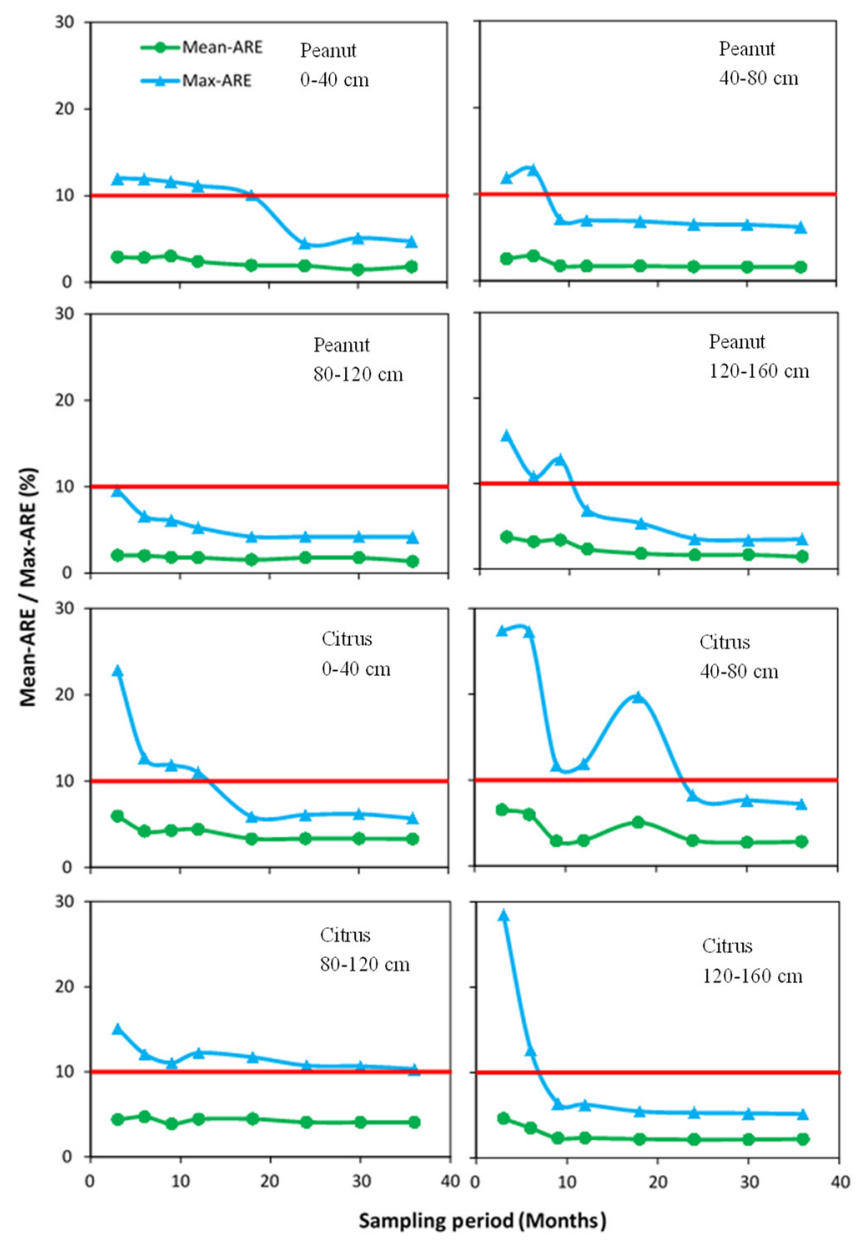

Fig. 7. Changes of prediction accuracy of soil water content (SWC) with eight total sampling durations for peanut (a) and citrus (b) sites at $0-40,40-80,80-120$, and $120-160 \mathrm{~cm}$ soil layers during the validation period (from July, 2016 to December, 2016), represented by the mean value and maximum of absolute value of relative error, Mean-ARE and Max-ARE, respectively.

Watts, 1968). In other words, a stronger "aliasing" effect was always detected with changing spatial or temporal sampling spacing or interval, than for changes in the sampling duration or monitoring period. This "aliasing" effect has previously been reported for studies in groundwater (Gelhar, 1993), soil moisture (Western and Blöschl, 1999), and soil saturated hydraulic conductivity (Gao et al., 2012). In this study, temporal stability information of SWC which "folded back" from low sampling frequency to high frequency might be responsible for the stronger influences of sampling period than sampling frequency on temporal stability of SWC. This is supported by earlier findings by Western and Blöschl (1999), who found that sample spacing had no effect on the apparent variance of SWC, which was ascribed to the "aliasing" effect. Relatively small impacts of sampling frequency on temporal stability of SWC extended previous reports by Rivera et al. (2014) who found that the temporal stability did not change with sampling intervals in a limited range from 7 to 28 days in the Central Valley of Chile. However, Gao et al. (2012) predicted that this "folded back" phenomenon would diminish or even disappear with increasing sampling intervals. This might explain that larger differences were eventually observed when sampling intervals were very high (e.g. 210 days or 240 days). 


\section{Wider implications for sampling strategy design}

The temporal stability index (i.e. SDRD) was more sensitive to the duration of the sampling period than the sampling interval. Therefore, it is reasonable to suggest that for a given number of sampling occasions, it would be best to target occasions that capture the longer term natural variability in moisture conditions. In other words, it would be recommended to focus on long term monitoring rather than high frequency (short intervals) monitoring. In comparison to decreasing sampling intervals, a good distribution of limited sampling occasions within a long sampling period was more efficient to decrease the uncertainty in the temporal stability. For example, this can be demonstrated clearly by comparing results from two cases (C1 and $\mathrm{C} 2$ ) with similar sampling occasions but diverse sampling strategies: e.g. $\mathrm{C} 1$ with a 45-day sampling interval over a 36-month period ( 22 occasions) and C2 with a 15-day sampling interval over a 12-month period (23 occasions). Significant differences in the errors $(\mathrm{p}<0.01$, t-test) between the two strategies indicated that it was reasonable to spend more effort extending the sampling period than improving frequency, when balancing between cost and accuracy.

The required sampling strategy differed when only considering the scale effect and considering errors both from sampling scale and uncertainties. By evaluating the mean over all the sub-datasets, the errors of such values were caused only by temporal scale effects. For similar study sites, any sampling strategy with a sampling interval shorter than 240 days and a sampling period no shorter than 12 months with measurement occasions more than 5 may be recommended. However, it should be noted that here we employed a single sampling and did not collect all possible sub-datasets within the actual sampling strategy, which has inevitably introduced uncertainties by ignoring variations between sites. It would therefore be necessary to extend the temporal sampling scales to decrease the uncertainties.

Considering the error both from sampling scale and uncertainties, sampling once every 45 days over 24 months could result in errors less than $10 \%$ in most cases (Table 4). Since we intentionally explored sampling strategies for a case study with high variability in hydroclimatologic and related SWC, we assume that these recommendations would be appropriate for a large range of sites, and certainly for those sites exposed to less variability. To be safe in practice, a 45-day sampling interval is suggested to minimize potential impacts from more variable years or crops that may alter SWC dynamics even more than citrus. Clearly, there is a need for more data from (sub)tropical climates to explore a broader range of vegetation, soil management and soil characteristics.

Similar sampling frequencies were also recommended by Martínez-Fernández and Ceballos (2005) who suggested to sample monthly for a temporal stability study in the central sector of the Duero basin, Spain. The importance of keeping a suitable sampling frequency to get insights of seasonal processes was previously emphasized by Guber et al. (2008) and Rivera et al. (2014). A complete seasonal cycle was important to capture seasonal dynamics of temporal stability caused by season-variable hydro-climatological conditions and vegetation phenology (Wang et al., 2015a). Nevertheless, the sampling period proposed in this study is also longer than reported previously, such as a one-year sampling period suggested by Martínez-Fernández and Ceballos (2005). A longer sampling period may be needed to account for the strong inter-annual variation of meteorological factors among the three-year study period, e.g. with rainfall of 1351, 1939 and $2193 \mathrm{~mm}$, in consecutive years respectively (Fig. 3). Different rainfall total between years would affect the relationships between temporal stability and related factors. For example, Wang et al. (2015a) reported a significant decrease in the effects of vegetation on temporal stability when rainfall increased from $566 \mathrm{~mm}$ to $604 \mathrm{~mm}$ in a semi-arid grassland.

There were no consistent differences observed in the identified most efficient sampling strategies for the different vegetation types and soil depths, as noted above. With regards to the Max-AREs of SDRD, the recommended sampling frequency for peanut was greater at $0-40 \mathrm{~cm}$, smaller at $40-80$ and $80-$ $120 \mathrm{~cm}$, and comparable at $120-160 \mathrm{~cm}$ than citrus site (Table 5). This suggests that the critical requirements could not be explained only by detected differences in spatio-temporal patterns between vegetation types and among soil depths. Other factors, such as extreme weather conditions, preferential flow pathways and "hotspots" of subsurface flow might play an important role in determining such requirements. Dynamics of preferential flow or subsurface flow can result in varying relationships between SWC at different spatial locations (Zhu et al., 2017).

Finally, dynamics in rainfall result in another important factor that can affect the temporal stability behavior of SWC (Lee and Kim, 2017). While the exact influences of rainfall event dynamics on key hydrological processes also depend on local conditions (e.g. soils, slope position and microtopography), it is known that during and directly after rainfall events, these can be different from before. There is additional work needed to evaluate if and how such effects translate into changes of temporal stability behavior. Such information is critical to arrange sampling dates (e.g. with respect to occurrence of the rainfall events) that allow for capturing accurate temporal stability information of SWC. To our knowledge, previous studies have not taken this into account and mainly focused on year- or season-scale. Instead, those and the study employed a middle way to eliminate immediate rainfall event effects, i.e. all the sampling occurred at least two days after a rainfall event. As such, by excluding rainfall event conditions, we recognize that this may still result in a departure of observed data from "real world" situations to some extent, yet we focused here on the key longer term patterns. The effect of short term rainfall dynamics on temporal stability behavior should receive more attention in the future. This would require higher temporal resolution data collection than employed here.

\section{CONCLUSIONS}

Impacts of temporal sampling strategy on temporal stability behaviors of SWC were analyzed for peanut and citrus sites at four soil layers from a 3.5-year dataset (from July, 2013, to December, 2016) in the subtropical Chinese red soil region. The following conclusions were drawn:

(1) Vegetation type played an important role in affecting spatio-temporal SWC patterns. In the present study, SWC at the peanut site exhibited less temporal variation, stronger temporal stability and greater prediction accuracy of mean SWC compared to the citrus site $(\mathrm{p}<0.05$, paired samples t-test). These differences were mainly caused by the diverse characteristics of the vegetation itself, e.g. root water uptake.

(2) With increasing sampling interval or decreasing monitoring duration, temporal stability of SWC was generally overestimated and affected more by the duration of the total sampling period than the interval between sampling occasions. With increasing intervals between sampling occasions, errors of temporal stability were mainly caused by the increasing uncer- 
tainties and with decreasing sampling periods, however, the errors caused by scale effect and uncertainties were comparable.

(3) Sampling design strategies in future studies on temporal stability of SWC should consider distributing limited sampling occasions over a long sampling period, rather than focusing on high frequency sampling. More specifically, balancing cost and accuracy, a sampling strategy with 45-day sampling interval over 24 months is recommended in study areas similar to our site. If only mean SWC prediction is desired, the sampling interval and period duration could be further decreased. No significant differences between recommended sampling strategies were observed for peanut and citrus sites among four different soil layers. Therefore, employing uniform sampling strategies for different vegetation types and soil layer depths was reasonable here.

Although precise recommended sampling strategies are referential to areas with the same or similar climates, vegetation types and soils, the need for long-term rather than high frequency monitoring has wider applications. Nevertheless, for areas where differences in spatial patterns for SWC inter- or intra-seasons is weak, it is reasonable to infer that required sampling intervals and sampling periods could be less. Since previous studies have speculated that the effects of sampling strategies might be more variable under climates with strong seasonality, we consider that the results here represent an extreme scenario that allows for widespread adoption.

Acknowledgements. Financial support for this research was provided through the joint China-UK Red Soil Critical Zone project funded by the National Natural Science Foundation of China (NSFC: 41771263; 41571130053) and the United Kingdom Natural Environment Research Council (NE/N007611/1). Additional funding was provided by the "135 innovation project" from the Chinese Academy of Sciences (CAS:ISSASIP1648). Special thanks go to the staff of the Ecological Experimental Station of Red Soil of the Institute of Soil Science of CAS.

\section{REFERENCES}

Biswas, A., 2014. Season- and depth-dependent time stability for characterizing representative monitoring locations of soil water storage in a hummocky landscape. Catena, 116, $38-50$.

Biswas, A., Si, B.C., 2011. Identifying scale specific controls of soil water storage in a hummocky landscape using wavelet coherency. Geoderma, 165, 50-59.

Boulet, A., Prats, S.A., Malvar, M.C., González-Pelayo, O., Coelho, C.O.A., Ferreira, A.J.D., Keizer, J.J., 2015. Surface and subsurface flow in eucalyptus plantations in northcentral Portugal. J. Hydrol. Hydromech., 63, 193-200.

Brandyk, A., Kiczko, A., Majewski, G., Kleniewska, M., Krukowski, M., 2016. Uncertainty of Deardorff's soil moisture model based on continuous TDR measurements for sandy loam soil. J. Hydrol. Hydromech., 64, 23-29.

Brocca, L., Melone, F., Moramarco, T., Morbidelli, R., 2010. Spatial-temporal variability of soil moisture and its estimation across scales. Water Resour. Res., 46, W02516.

Burns, T.T., Berg, A.A., Cockburn, J., Tetlock, E., 2016. Regional scale spatial and temporal variability of soil moisture in a prairie region. Hydrol. Process., 30, 3639-3649.

Buttafuoco, G., Castrignanò, A., Castrignano, E., Dimase, A.C., 2005. Studying the spatial structure evolution of soil water content using multivariate geostatistics. J. Hydrol., 311, 202-218.
Canton, V., Rodríguez-Caballero, E., Contreras, S., Villagarcia, L., Li, X.Y., Solé-Benet, A., Domingo, F., 2016. Vertical and lateral soil moisture patterns on a Mediterranean karst hillslope. J. Hydrol. Hydromech., 64, 209-217.

Cassel, D.K., Wendroth, O., Nielsen, D.R., 2000. Assessing spatial variability in an agricultural experiment station field: opportunities arising from spatial dependence. Agron. J., 92, $706-714$.

Cho, E., Zhang, A., Choi, M., 2016. The seasonal difference in soil moisture patterns considering the meteorological variables throughout the Korean peninsula. Terr. Atmos. Ocean. Sci., 27, 907-920.

Choi, M., Jacobs, J.M., 2007. Soil moisture variability of root zone profiles within SMEX02 remote sensing footprints. Adv. Water Resour., 30, 883-896.

Cosh, M.H., Jackson, T.J., Bindlish, R., Prueger, J.H., 2004. Watershed scale temporal and spatial stability of soil moisture and its role in validating satellite estimates. Remote Sens. Environ., 92, 427-435.

Cosh, M.H., Jackson, T.J., Starks, P., Heathman, G., 2006. Temporal stability of surface soil moisture in the Little Washita River watershed and its applications in satellite soil moisture product validation. J. Hydro., 323, 168-177.

Dumedah, G., Coulibaly, P., 2011. Evaluation of statistical methods for infilling missing values in high-resolution soil moisture data. J. Hydrol., 400, 95-102.

Fader, M., von Bloh, M., Shi, S., Bondeau, A., Cramer, W., 2015. Modelling Mediterranean agro-ecosystems by including agricultural trees in the LPJmL model. Geosci. Model. Dev., 8, 3545-3561.

Gao, L., Shao, M.A., Wang, Y.Q., 2012. Spatial scaling of saturated hydraulic conductivity of soils in a small watershed on the Loess Plateau, China. J. Soils Sediments, 12, 863-875.

Gao, L., Shao, M.A., Peng, X.H., She, D.L., 2015a. Spatiotemporal variability and temporal stability of water contents distributed within soil profiles at a hillslope scale. Catena, 132, 29-36.

Gao, L., Lv, Y.J., Wang, D.D., Tahir, M., Peng, X.H., 2015 b. Can shallow-layer measurements at a single location be used to predict deep soil water storage at the slope scale? J. Hydrol., 531, 534-542.

Gao, L., Lv, Y.J., Wang, D.D., Tahir, M., Biswas, A., Peng, X.H., 2016a. Soil water storage prediction at high spacetime resolution along an agricultural hillslope. Agric. Water Manag., 165, 122-130.

Gao, X.D., Zhao, X.N., Brocca, L., Lv, T., Huo, G.P., Wu, P.T., 2016b. Upscaling of soil moisture content from surface to profile: multistation testing of observation operators. Hydrol. Earth Syst. Sci. Discuss. DOI: 10.5194/hess-2016-617.

Gelhar, L.W., 1993. Stochastic Subsurface Hydrology. Prentice Hall, Englewood Cliffs, 390 p.

Guber, A.K., Gish, T.J., Pachepsky, Y.A., van Genuchten, M.T., Daughtry, C.S.T., Nicholson, T.J., Cady, R.E., 2008. Temporal stability in soil water content patterns across agricultural fields. Catena, 73, 125-133.

Heathman, G.C., Larose, M., Cosh, M.H., Bindlish, R., 2009. Surface and profile soil moisture spatio-temporal analysis during an excessive rainfall period in the Southern Great Plains, USA. Catena, 78, 159-169.

Hu, W., Tallon, L.K., Si, B.C., 2012. Evaluation of time stability indices for soil water storage upscaling. J. Hydrol., 475, 229-241.

Hu, W., Si, B.C., 2016. Estimating spatially distributed soil water content at small watershed scales based on decomposi- 
tion of temporal anomaly and time stability analysis. Hydrol. Earth Syst. Sci., 12, 6467-6503.

Jarasiunas, G., Kinderiene, L., 2016. Impact of agroenvironmental systems on soil erosion processes and soil properties on hilly landscape in Western Lithuania. J. Environ. Eng. Landsc., 24, 60-69.

Jenkins, G.M., Watts, D.G., 1968. Spectral Analysis and its Applications. Holden-Day, San Francisco, 525 p.

Junqueira Junior, J.A., Mello, C.R., Owens, P.R., Mello, J.M., Curi, N., Alves, G.J., 2017. Time-stability of soil water content (SWC) in an Atlantic Forest - Latosol site. Geoderma, 288, 64-78.

Korres, W., Reichenau, T.G., Fiener, P., Koyama, C.N., Bogena, H.R., Cornelissen, T., Baatz, R., Herbst, M., Diekkrüger, B., Vereecken, H., Schneider, H., 2015. Spatiotemporal soil moisture patterns - A meta-analysis using plot to catchment scale data. J. Hydrol., 520, 326-341.

Lai, R., 1998. Soil erosion impact on agronomic productivity and environment quality. Crit. Rev. Plant Sci., 17, 319-464.

Lee, E., Kim, S., 2017. Pattern similarity based soil moisture analysis for three seasons on a steep hillslope. J. Hydrol., 551, 484-494.

Li, X.Z., Shao, M.A., Jia, X.X., Wei, X.R., 2016. Profile distribution of soil-water content and its temporal stability along a 1340-m long transect on the Loess Plateau, China. Catena, $137,77-86$.

Liu, B.X., Shao, M.A., 2014. Estimation soil water storage using temporal stability in four land uses over 10 years on the Loess Plateau, China. J. Hydrol., 517, 974-984.

Martínez-Fernández, J., Ceballos, A., 2005. Mean soil moisture estimation using temporal stability analysis. J. Hydrol., 312, 28-38.

Martínez, G., Pachepsky, Y.A., Vereecken, H., 2014. Temporal stability of soil water content as affected by climate and soil hydraulic properties: a simulation study. Hydrol. Process., 28, 1899-1915.

Martini, E., Wollschläger, U., Kögler, S., Behrens, T., Dietrich, P., Reinstorf, F., Schmidt, K., Weiler, M., Werban, U., Zacharias, S., 2015. Spatial and temporal dynamics of hillslope-scale soil moisture patterns: Characteristic states and transition mechanisms. Vadose Zone J., 14, 4, vzj2014.10.0150. DOI: 10.2136/vzj2014.10.0150.

Nasta, P., Penna, D., Brocca, L., Zuecco, G., Romano, N., 2018. Downscaling near-surface soil moisture from field to plot scale: A comparative analysis under different environmental conditions. J. Hydrol., 557, 97-108.

Pan, F., Pachepsky, Y., Jacques, D., Guber, A., Hill, R.L., 2012. Data assimilation with soil water content sensors and pedotransfer functions in soil water flow modeling. Soil Sci. Soc. Am. J., 76, 829-844.

Rivera, D., Lillo, M., Granda, S., 2014. Representative locations from time series of soil water content using time stability and wavelet analysis. Environ. Monit. Assess., 186, 9075-9087.

Shen, Q., Gao, G.Y., Hu, W., Fu, B.J., 2016. Spatial-temporal variability of soil water content in a cropland shelterbeltdesert site in an arid inland river basin of Northwest China. J. Hydrol., 540, 873-885.
Soil Survey Staff, 2010. Keys to Soil Taxonomy. $11^{\text {th }}$ ed. United States Department of Agriculture, Natural Resources Conservation Service, Washington, $338 \mathrm{p}$.

Starks, P.J., Heathman, G.C., Jackson, T.J., Cosh, M.H., 2006. Temporal stability of soil moisture profile. J. Hydrol., 324, 400-411.

Stockinger, M.P., Bogena, H.R., Lücke, A., Diekkruger, B., Weiler, M., Vereecken, H., 2014. Seasonal soil moisture patterns: Controlling transit time distributions in a forested headwater catchment. Water Resour. Res., 50, 5270-5289.

Tahir, M., Lv, Y.J., Gao, L., Hallett, P.D., Peng, X.H., 2016. Soil water dynamics and availability for citrus and peanut along a hillslope at the Sunjia Red Soil Critical Zone Observatory (CZO). Soil Till. Res., 163, 110-118.

Vachaud, G., Passerat De Silans, A., Balabanis, P., Vauclin, M., 1985. Temporal stability of spatially measured soil water probability density function. Soil Sci. Soc. Am. J., 49, 822-828.

Vanderlinden, K., Vereecken, H., Hardelauf, H., Herbst, M., Martínez, G., Cosh, M.H., Pachepsky, Y., 2012. Temporal stability of soil water contents: A review of data and analysis. Vadose Zone J., 11, 4, vzj2011.0178. DOI: 10.2136/vzj2011.0178.

Wang, T.J., Wedin, D.A., Franz, T.E., Hiller, J., 2015a. Effect of vegetation on the temporal stability of soil moisture in grass-stabilized semi-arid sand dunes. J. Hydrol., 521, 447459.

Wang, Y.Q., Hu, W., Zhu, Y.J., Shao, M.A., Xiao, S., Zhang, C.C., 2015b. Vertical distribution and temporal stability of soil water in 21-m profiles under different land uses on the Loess Plateau in China. J. Hydrol., 527, 543-554.

Wang, T.J., Liu, Q., Franz, T.E., Li, R.P., Lang, Y.C., Fiebrich, C.A., 2017. Spatial patterns of soil moisture from two regional monitoring networks in the United States. J. Hydrol., 552, 578-585.

Western, A.W., Blöschl, G., 1999. On the spatial scaling of soil moisture. J. Hydrol., 217, 203-224.

Zhang, P.P., Shao, M.A., Zhang, X.C., 2015. Scale-dependence of temporal stability of surface-soil moisture in a desert area in northwestern China. J. Hydrol., 527, 1034-1044.

Zhang, Z.B., Lin, L, Wang, Y., Peng, X.H., 2016. Temporal change in soil macropores measured using tension infiltrometer under different land uses and slope positions in subtropical China. J. Soils Sediments, 16, 854-863.

Zhao, Y., Zhang, B., Hill, R., 2012. Water use assessment in alley cropping systems within subtropical China. Agroforest Syst., 84, 243-259.

Zhu, Q., Zhou, Z.W., Duncan, E.W., Lv, L.G., Liao, K.H., Feng, H.H., 2017. Integrating real-time and manual monitored data to predict hillslope soil moisture dynamics with high spatio-temporal resolution using linear and non-linear models. J. Hydrol., 545, 1-11.

Zreda, M., Shuttleworth, W., Zeng, X., Zweck, C., Desilets, D., Franz, T., Rosolem, R. 2012. COSMOS: the cosmic-ray soil moisture observing system. Hydrology and Earth System Sciences, 16, 4079-4099.

Received 23 January 2018 Accepted 5 September 2018 